\title{
Constipation Is Also an Important Cause of Fecal Incontinence in Old People: Author's Reply
}

TO THE EDITOR: I would like to thank Dr. Lee for his thoughtful comments ${ }^{1}$ on the impact of constipation on fecal incontinence. ${ }^{2}$ The coexistence of fecal incontinence and constipation has been well characterized in children and the geriatric population. Fecal incontinence in children is secondary to 'overflow' which results from the presence of constipation. ${ }^{3}$ Also fecal incontinence occurs in a variety of organic disorders like congenital malformations, neurogenic problems like myelomeningocele, and other conditions affecting the anorectum, anal sphincters, or the spinal cord. $^{4}$

However, there is limited data in non-geriatric adults. Fecal incontinence in adults is frequently associated with urge and diarrhea and is considered in chronic medical conditions, such as Parkinson's disease, or acquired through local pelvic floor dysfunction via trauma or surgery. ${ }^{5}$ Female predominance in fecal incontinence is regarded as the result of sphincter disruption secondary to obstetric injury. Under these conditions, fecal incontinence is easily presented if the patients have loose stool or diarrhea. The population based study for incidence of fecal incontinence showed that a higher prevalence of diarrhea and a higher probability of pelvic dysfunction might account for the higher prevalence of fecal incontinence at young women. ${ }^{6}$ In this study, urgency was a risk factor for development of fecal incontinence. $^{6}$

In non-geriatric constipated adults, fecal incontinence is detected with similar proportion according to gender. In our study, there was no definitive gender difference in the prevalence of fecal incontinence and it is consistent with other population based study. ${ }^{6}$ Recent studies showed that a significant proportion of men with fecal incontinence had a history of perianal disease including hemorrhoids and surgical procedure. ${ }^{7}$ However, in some non-geriatric male patients with fecal incontinence, fecal impaction may also occur due to a combination of impaired rectal sensitivity (hyposensitivity), increased rectal compliance and in- creased rectal dimensions; these factors contribute to fecal retention by decreasing the frequency and intensity of the desire. ${ }^{8}$ Fecal seepage presents as the unintentional loss of small amount of stool, usually in the hours following defecation. Such seepage, clinically distinct from more major passive or urge-related fecal incontinence, occurs in patients with incomplete rectal evacuation, secondary to a dyssynergic pattern of defecation. ${ }^{9}$ However, our study did not show the strong association of constipation and fecal incontinence in young adult group, which is not clear whether it is the result of true negative association or type II error is.

In geriatric and non-geriatric patients with fecal incontinence, both diarrhea and constipation may be the important risk factors for fecal incontinence. Fecal incontinence may be sub-classified by associated symptom patterns or underlying pathophysiology. Further meticulous investigation would improve understanding of risk factors coupled with diagnostic techniques and treatments, thereby improving outcomes in fecal incontinence.

Hye-Kyung Jung

Department of Internal Medicine, Ewha Medical Research Institute, Ewha Womans University School of Medicine, Seoul, Korea

1. Lee TH. Constipation is also an important cause of fecal incontinence in old people. J Neurogastroenterol Motil 2012;18:345.

2. Kang HW, Jung HK, Kwon KJ, et al. Prevalence and predictive factors of fecal incontinence. J Neurogastroenterol Motil 2012;18:8693.

3. Rasquin A, Di Lorenzo C, Forbes D, et al. Childhood functional gastrointestinal disorders: child/adolescent. Gastroenterology 2006; 130:1527-1537.

4. Constipation Guideline Committee of the North American Society for Pediatric Gastroenterology, Hepatoloty and Nutrition. Evaluation and treatment of constipation in infants and children: recommendations of the North American Society for Pediatric Gastroenterology, Hepatology and Nutrition. J Pediatr Gastroenterol Nutr 
2006;43:e1-e13.

5. Burgell RE, Bhan C, Lunniss PJ, Scott SM. Fecal incontinence in men: coexistent constipation and impact of rectal hyposensitivity. Dis Colon Rectum 2012;55:18-25.

6. Rey E, Choung RS, Schleck CD, Zinsmeister AR, Locke GR 3rd, Talley NJ. Onset and risk factors for fecal incontinence in a US community. Am J Gastroenterol 2010;105:412-419.

7. Maeda Y, Vaizey CJ, Hollington P, Stern J, Kamm MA. Physiological, psychological and behavioural characteristics of men and women with faecal incontinence. Colorectal Dis 2009;11:927-932.
8. Gladman MA, Lunniss PJ, Scott SM, Swash M. Rectal hyposensitivity. Am J Gastroenterol 2006;101:1140-1151.

9. Rao SS, Ozturk R, Stessman M. Investigation of the pathophysiology of fecal seepage. Am J Gastroenterol 2004;99:2204-2209.

\section{Conflicts of interest: None.}

